\title{
The Interactions Between the USD to VND Rate and Stock Index in Vietnam: An Application of VECM Model
}

\author{
Nguyen Thi Nhung \\ Faculty of Finance and Banking \\ University of Economics and Business - Vietnam National University \\ 144 Xuan Thuy, Cau Giay, Hanoi \\ nguyenthinhung.1684@gmail.com
}

\begin{abstract}
Ths working paper examined the USD to VND exchange rate and VN-Index interactions with VECM model using daily data from November 2012 to June 2021. To be precise, the research compares impacts of the USD to VND exchange rate on $\mathrm{VN}$-Index in two distinct sub-periods, including the first one from November 2012 to December 2015 and the second one from January 2016 to June 2012 because of the introduction of the decision 2730 /QĐ-NHNN about the daily average inter-bank exchange rate between VND and foreign currencies in 2016. The results of VECM show that there are stable long-term and short-run relationships between the USD to VND exchange rate and VN-Index. These interactions are stricter in the first sub-period or before the introduction of decision 2730/QĐ-NHNN, leading to some important implications which are signficiant for portfolio managers' making-decision about the portfolio diversification and risk management.

Index Terms-USD to VND Exchange Rate, VN-Index, Stock exchange, VECM
\end{abstract}

\section{INTRODUCTION}

I $\mathrm{N}$ PRINCIPLES, the intereaction between exchange rate and stock market is explained through two following theories: (i) From the traditional approach's perspective, exchange rate fluctuations have impacts on have impacts on firms' values by making changes in the competitiveness as well as their firm value which is quoted in foreign currency. In other words, exchange rates should lead stock prices; (ii) By contrast, the portfolio approach indicates that prices of stock index would negatively collarate with the rate of exchange. To be precise, domestic investor's wealth can increase in case of a growth in stock prices, resulting to a higher demand for money and interest rates. Many studies have focused on the relationship between rates of exchange and stock index, but their research results are not significantly homogeneous on different markets.

In Vietnam, the stock market is dominated by retail investors investors with the rate of more than $90 \%$ who follows herd behaviour. Vietnamese individual investors dont have a long-term vision and they are willing to accept high risks. The current situation in Vietnam totally supports theories about the behavioral finance and feedback trading model by showing that many Vietnamese investors' psychology may be significantly affected by macroeconomic events like exchange rate. Changes in exchange rate surely affect investors sentiment with raising concerns about Vietnam's foreign exchange reserves and issues about inflation and national debt. So, rate of exchange is a factor that can strongly influence market movements.
In particular, on December 31, 2015, the State Bank of Vietnam (SBV) issued the Decision 2730/QĐ-NHNN announcing the changes in calculating the exchange rate of VND to other currencies, which officially took effect on January 4, 2016. Therefore, since 2016 the central rate of VND to USD has been calculated on the basis of reference to the inter-bank average VND/USD exchange rate. This decision is considered a new progress managing exchange rate which allows Vietnam to depend on any partner, even major partners, thereby avoid adverse shocks from the market, leading to achieve macro-economy objectives about promoting national economy.

However, from our best knowledge, there is not any research which compare the interaction between the exchange rate and change in $\mathrm{VN}$-Index before and after the decision 2730/QĐ-NHNN. Therefore, this research aims to examine the long and short run relationship between the USD to VND exchange rate and stock market in Vietnam. To be precise, it is expected to determine how much changes in exchange rate have impacts on changes in VN-Index during a period from November 2012 to June 2021. The choice of research period primarily originated as a result of the fact that from Vietnamese financial experts' perspectives, November 2012 is marked by the mature of the stock market in Vietnam. Moreover, the Decision 2730/QĐ-NHNN is taken into account as an important event which allows this research compare the interactions between the USD to VND exchange rate and stock market in Vietnam in two different sub-periods, such as the first sub-period from November 2012 to December 2015 and the second sub-period form January 2016 to June 2021.

The study includes 5 sections. After introduction part, in Section 2, the article reviews the literature related to the interactions between rate of exchange and stock market. Section 3 describes data collection and vector error correction model (VECM) used as a method of data analysis. Section 4 describes about data and empirical results. Empirical results and discussions are presented in section 5 while section 6 gives some conclusions.

\section{Literature}

Several studies about the relationships between stock prices and exchanges rate have been executed on both developed and developing stock markets and provided different results on different markets. 
Research in 2016 tries to test the intereaction between these two mentioned variables in Brazil by using linear and nonlinear causality test [1]. As a result, the author dont find evidence about the long-run relationship but support linear Granger causality while the opposite result is found in the relation from rates of exchange to stock index. To be precise, stock index negatively impacts rates of exchange while the later also lead the former.

A test about the relationship between exchange rate of exchange and stock price is executed in Indonesia, Singapore, Thailand, the Philippines and Malaysia from 1993 to 2006 with Engle-Granger test [2]. The results show a cointegration between these two variables. However, this relation cannot be clearly defined.

Similarly, the relationship between currencies, including the euro, the pound, the yuan, and the yen and the U. S. stock from 2000 to 2012 is tested [2]. By using the regression model, the research figures out the negative relationship between the Japanese yen and the U.S. stock market but the positive correlation between the U.S. stock and euro and the pound. Moreover, the relationship between the yuan to USD and stock index is possitive but not significant while the Chinese government have taken measures to directly intervene the forex market in an attempt to encourage export activities to countries [3].

Besides regression model, there are different methods used to investigate this relation. Firstly, VECM model is used as a method of data analysis to verify the impact of rate of exchange on stock market in Pakistan [4]. By using daily data of KSE-100 and currency rate between Pak Rupee and the US dollar, the research results indicate that both two variables are independent of each other. In other word, there is no evidence supporting this relationship. Furthermore, multivariate VAR-GARCH is also used to investigate the interactions between stock index and rate of exchange. The data are monthly collected from January 2000 to October 2014 [5]. As a result, there is a stable long-term relationship between stock prices and rates of exchange. Moreover, a significant impact from stock market to rates of exchange is found while the opposite relation is not justified [5]. In addition, non-autogressive distributed lag (ARDL) analysis is also an approach method to investigate the impact of change in rate of exchange on stock index in Vietnam [6]. Monthly data about VN-Index and the VND to USD rate are collected over a period from 2001 to 2018. Authors compare this relationship between the currency appreciation and the currency depreciation. As a result, changes on rate of exchange significangtly impact stock index both in long and short terms. In addition, stock prices have a stronger influence on exchange rate during the currency appreciation than during the currency depreciation [6]

Besides studies which directly investigate impacts of exchange rate on stock market, some studies highlight that it is necessary to include other assets such as currencies, commodities, and bonds when considering the integration or interdependence of stock markets [7] and also totally agree that portfolio management should take into account the integration and connections between asset classes since they are really meaningful for both investors and policymakers when they make decisions [8] [9].
Focusing on the association between oil and stock returns in East Asian countries, during the period from 1992 to 2015, the research figures that oil prices have impacts on to stock returns in the long run although the two variables experience different fluctuations in distinct periods [10]. In line with this topic, the research in India strongly justiies the interdependence between price of oil and daily stock returns during a period from 1999 to 2021 [11]. Moreover, there is evidence on the co-movement between prices of crude oile and maize, price of soybeans and the rate of exchange, as well as price of sugar and acitivites of global economy [12]. Similarly, long-term linkages between stock returns and prices of commodities are also justified in Africa [13].

\section{Methodology}

\section{A. Data collection}

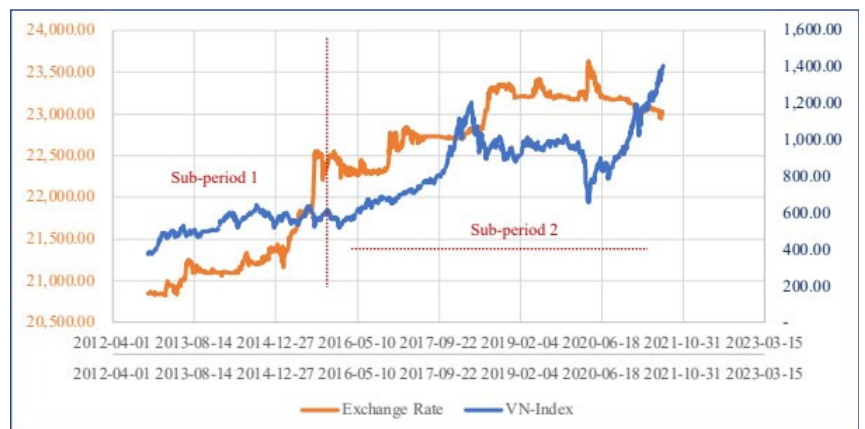

Fig 1. Fluctuation of USD to VND exchange rate and VN-Index from November 2012 to December 2016

Data used in this study are sourced from Investing.com and consist of VN-Index on HOSE and the USD to VND exchange rate over a period from November 2012 to June 2021. Figure 1 shows fluctuations of VN-Index and the USD to VND exchange rate in two different sub-periods. It can clearly be seen that changes in exchange rate were smaller than those in VN-Index during the first sub-period while the second one experienced the opposite situation. Moreover, the USD to VND exchange rate have slightly fluctuated since January 2016, compared to an increase in exchange rate from November 2012 to December 2015. By contrast, there have been significant fluctuations in VN-Index since 2016 while this index remained quite stable before changes in determining the daily average inter-bank exchange rate between Vietnam dong and foreign currencies in Vietnam.

\section{B. Data Analysis}

The correlation between the USD to VND exchange rate and VN-Index is determined through 4 main steps, starting with stationarity test and ending with Vector Error Correction Model. At the first stage, Augmented Dickey-Fuller test is used to test stationary of changes in exchange rate $\left(\Delta E X_{t}\right)$ and changes in VN-Index $\left(\Delta S M_{t}\right)$. Variables are calculated as following:

$$
\Delta E X_{t}=\frac{\text { Exchangerate }_{t}-{\text { Exchange } \text { rate }_{t-1}}_{\text {Exchangerate }}}{\text { Ex-1 }}
$$




$$
\Delta S M_{t}=\frac{V n-\text { Index }_{t}-V n-\text { Index }_{t-1}}{V n-\text { Index }_{t-1}}
$$

Data analysis continues the second stage where optimal lag length is determined by using diferent crieteria such as Akaike information criterion (AIC), Schwarz information criterion (SC), FPE criterion, and Hannan Quinn information criterion (HQ). The next step is Johansen cointegration test. Next, the fourth step of VECM is executed in case of the value of Trace and Max Eigenvalue of biger than $5 \%$ critical value,

At the fourth stage, an estimated VECM is as below:

$$
\Delta S M_{t}=\beta_{0}+\sum_{j=1}^{n} \beta_{i} S M_{j, t-j}+\sum_{i=1}^{n} \delta_{i} \Delta E X_{i, t-i}+\omega \mu_{t-1}+v_{t}[1]
$$

Co-integrate equation (long-run model):

$$
\mu_{t-1}=E T C_{t-1}=\Delta S M_{j, t-1}-\beta_{0}-\beta_{1} \Delta E X_{i, t-1}
$$

While:

- $\Delta S M_{t}$ :Changes in VN-Index at time $\mathrm{t}$

- $\Delta E X_{t}$ :Changes in the USD to VND exchange rate at time $\mathrm{t}$

- $\mu_{t-1}$ :The lagged value of the error correction term

- $v_{t}$ : A white noise error term

Both the short-run and long-run dynamics between $\Delta S M_{t}$ and $\Delta E X_{t}$ are explained by the first equation while the second one only focuses on the long-run relationship. and $\Delta E X_{t}$ exists when the coefficient of the co-integrate equation is from -1 to 0 . The coefficient of ETC $\omega$ means how quickly $\Delta S M_{t}$ go to the balance point after the independent variable and $\Delta E X_{t}$ changes.

The entire process concludes after stability test of VECM model with the inverse roots of the characteristic AR polynomial test as well as CUSUM test.

\section{Research Results}

\section{A. Data Description}

The descriptive statistics about changes in the USD to VND exchange rate and VN-Index over a period from November 2012 to Jun 2021 are pressented in the table 1 . Overall, the USD to VND exchange rate experiences less significant fluctuation than VN-Index. To be precise, $\Delta S M$ has the min value of $-6.67 \%$ and the max value of $4.98 \%$ while those of $\triangle E X_{t}$ are $-1.135 \%$ and $1.38 \%$, leading to the standard deviation of $\Delta S M_{t}$ is $1.09 \%$, compared to $0.11 \%$ of. The sub-period 1 and the sub-period 2 experience the same situation.

Table 1: Data Description

\begin{tabular}{|c|c|c|c|c|}
\hline & Min & Max & Mean & Standard deviation \\
\hline Sub-period 1 & & & & \\
\hline$\Delta S M_{t}$ & $-5.87 \%$ & $3.47 \%$ & $0.13 \%$ & $1.06 \%$ \\
\hline$\Delta E X_{t}$ & $-1.35 \%$ & $1.38 \%$ & $0.00 \%$ & $0.14 \%$ \\
\hline Sub-period 2 & & & & \\
\hline$\Delta S M_{t}$ & $-6.67 \%$ & $4.98 \%$ & $0.14 \%$ & $1.11 \%$ \\
\hline$\Delta E X_{t}$ & $-0.52 \%$ & $0.74 \%$ & $0.00 \%$ & $0.09 \%$ \\
\hline Total period & & & & $1.09 \%$ \\
\hline$\Delta S M_{t}$ & $-6.67 \%$ & $4.98 \%$ & $0.14 \%$ & $0.11 \%$ \\
\hline$\Delta E X_{t}$ & $-1.35 \%$ & $1.38 \%$ & $0.00 \%$ & \\
\hline
\end{tabular}

\section{B. Empirical Results}

Appendixes1 and 2 present VECM results for the subperiod 1 and the sub-period 2, accordingly. It can clearly seen that a regression with intercept c and @trend shows no trend and intercept of series of changes in USD to VND exchange rate and those in VN-Index have during two research sub-periods from November 2012 to June 2021.

Table 2 gives information about optimal lags, and coefficients of ETC between $\Delta S M_{t}$ and $\Delta E X_{t}$ before and after the Decision 2730/QĐ-NHNN. To be precise, different criteria like AIC and FPE show that optimal lags between $\Delta S M_{t}$ and $\Delta E X_{t}$ in the first sub-period is 7 , compared to 2 in the second sub-period.

Regarding to co-integration, the Trace and Max-Eigenvalue tests indicate a cointegration at the $5 \%$ between $\Delta S M_{t}$ and $\Delta E X_{t}$ if the probability is smaller than 0.05 . So, it can be obviously seen that there is co-integration between $\Delta S M_{t}$ and $\Delta E X_{t}$ during two research sub-periods from November 2012 to June 2021.

Table 2: Optimal Lags and Coefficients of ETC Between $\Delta S M_{t}$ and $\Delta E X_{t}$ in Two Different Sub-Periods

\begin{tabular}{|l|c|c|}
\hline & Optimal lags & Coefficient of ETC \\
\hline Sub-period 1 & 7 & -0.543357 \\
\hline Sub-period 2 & 2 & -0.141311 \\
\hline
\end{tabular}

Moreover, the coefficients of ETC between $\Delta S M_{t}$ and $\Delta E X_{t}$ are -0.543357 and -0.141311 for the sub-period 1 and the sub-period 2, accordingly. These values are bigger than -1 and smaller than 0 , confirming a total long-run relationship between $\Delta S M_{t}$ and $\Delta E X_{t}$ over a period from November 2012 to June 2021.

Notwithstanding the above, Wald test obviously shows evidence about the short-run relationship between $\Delta S M_{t}$ and $\Delta E X_{t}$ in both two sub-periods since p-values of F-statistic and Chi-square are less than 0.05 . In addition, the test of the autocorrelation of residuals indicates that all indices have $\mathrm{p}$ values less than 5\% significant level.

\section{Discussion}

Firstly, this research confirm both long-run and short-run relationships between the USD to VND exchange rate and VN-Index, supporting both two main theories, such as the traditional approach and the portfolio approach. This means that the USD to VND exchange rate can lead VN-Index while changes in VN-Index also has negative impacts on changes on the USD to VND exchange rate. Furthurmore, rhe results of this study are entirely consistent with the findings of [1], [3], [5], [6] but totally different with what [4] found out in their working paper.

Secondly, there are significant differences in relationships between the USD to VND exchange rate and VN-Index in the sub-period 1 and the sub-period 2, which can be translated through optimal lags and coefficients of ETC. To be precise, that optimal lags between $\Delta S M_{t}$ and $\Delta E X_{t}$ in the first sub-period is 7, compared to 2 in the second subperiod. In other words, a change in the USD to VND exchange rate has impacts on VN-Index during 7 next days in the sub-period 1, compared to only 2 next days in the subperiod 2. In addition, the coefficients of ETC between 
$\Delta S M_{t}$ and $\Delta E X_{t}$ are -0.543357 and -0.141311 for the subperiod 1 and the sub-period 2, accordingly. This means that a change in the USD to VND can lead a more significant fluctuation in VN-Index in the first sub-period than in the second sub-period.

In fact, the central rate mechanism ensures that the exchange rate is flexibly adjusted in line with what is happening in the market and is also regulated by the State Bank when the market witnesses complicated movements. The continuous fluctuations of the exchange rate reflecting the supply-demand relationship in the market will make it difficult for speculators to forecast rates of exchange, thereby reducing the act of holding foreign currencies as before. Moreover, the new exchange rate mechanism which is able to give clearer information can help participants to be fully active in their production investment activities. To be precise, they must be familiar with changes in exchange rate instead of a fairly stable exchange rate, leading to the fact that they have to improve their risk management. Furthurmore, the central exchange rate mechanism's flexibility and objective reflection of the supply-demand relationship is significantly considered a positive factor in attracting foreign investment into Vietnam. Therefore, it is argued that the central exchange rate mechanism is very flexible, making stable the foreign exchange market in Vietnam.

\section{Conclusion}

The result of VECM shows the high coefficient of the cointegrating equation and high coefficient of ETC between changes in the USD to VND exchange rate and VN-Index over a period from November 2012 to June 2021. In particular, this correlation have been lower since the Decision 2730/QĐ-NHNN about new calculation methods of determining the exchange rate between VND and foreign currencies. So, this research provides empirical evidences on relationship between rate of exchange and stock index in Vietnam. Investors can refere these results to choose an efficient investment strategy, making-decisions about portfolio diversification and risk management. However, it can be seen that this reasearch only give evidence about the intereaction between the USD to VND exchange rate and VN-Index but not explaine detailed ways where the exchange rate impacts changes in stock index. There is a need for further follow-up studies which focus much more on financial behaviors of retail investors in Vietnam towards changes in exchange rates in order to be able to provide deep analysis and highly specific recommendations.

\section{REFERENCES}

[1] Tabak, B.M. (2006). The Dynamic Relationship between Stock Prices and Exchange Rates: evidence for Brazil. Working paper series, 1-37.

[2] Harjito, D. A. (2009). Testing the relationship between exchange rate and stock price in the ASEAN countries. Economic journal of emerging markets, 3, 181-195.

[3] Bello Z. (2013). The association between exchange rates and stock returns. Investment Management and Financial Innovations, 3, 40-45.

[4] Suriani, S., Kumar, M.D., Jamil, F., Muneer, S. (2015). Impact of Exchange Rate on Stock Market. International Journal of Economics and Financial Issues, 5, 385-388.

[5] Manasseh, C. O., Chukwu, N. O., Abada, F.C., Ogbuabor, J. E., Lawal, A. I., Alio, F.C. (2019). Interactions between stock prices and exchange rates: An application of multivariate VAR-GARCH model. Cogent Economics \& Finance. 7:1, 1681573. https://doi.org/10.1080/ 23322039.2019.1681573

[6] Dang, V.C., Le, T.L., Nguyen, Q.K., Tran, D. Q. (2020). Linkage Between Exchange Rate and Stock Prices: Evidence from Vietnam. Journal of Asian Finance. Economics and Business, 12, 95-107.

[7] Bekaert, G., \& C. Harvey. (1997). Emerging equity market volatility. Journal of Financial Economics, 43(1), 29-77. https://doi.org/ 10.1016/S0304-405X(96)00889-6.

[8] Gilbert, C. (2009). Commodity speculation and commodity investments. ournal of Commodity Markets and Risk Management, 1-189.

[9] Yang, L., Garcia, P. (2014). Portfolio investment: are commodities useful?. Proceedings of the NCCC-134 Conference on Applied Commodity Price Analysis, Forecasting, and Market Risk Management, (p. 138). St. Louis, M.O.

[10] Xiao, C, Tian, C., Yuanb, N., Hamoric, Sh. (2017). Interdependence between oil and East Asian stock markets: Evidence from wavelet coherence analysis. Journal of International Financial Markets, Institutions and Money, 48, 206-223. https://doi.org/10.1016/ j.intfin.2017.02.001

[11] Das, S. (2020). The Time-Frequency Relationship between Oil Price, Stock Returns and Exchange Rate. Journal of Business Cycle Research. https://doi.org/10.1007/s41549-021-00057-3

[12] Fernandez-Diaz, J., \& Morley, B. (2019). Interdependence among agricultural commodity markets, macroeconomic factors, crude oil and commodity index. $J$ Research in International Business and Finance 47, 174-194.

[13] Boako, G., Alagidede. I., Sjo, B., \& Uddin, G. (2020). Commodities price cycles and their interdependence with equity markets. Energy Economics, 91. https://doi.org/10.1016/j.eneco.2020.104884. 